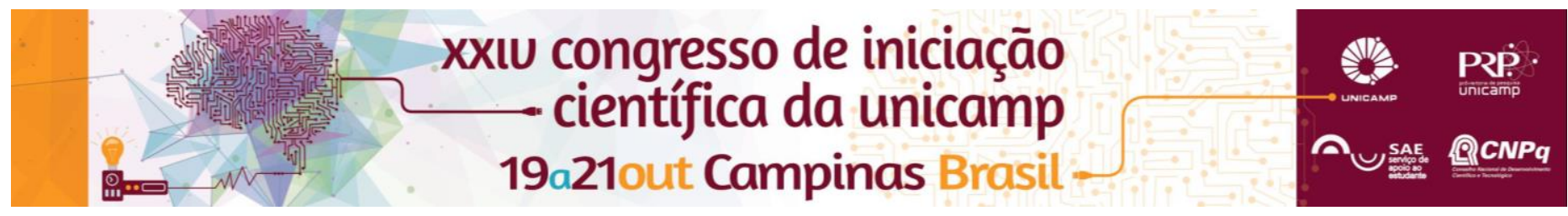

\title{
A dança e a recuperação da capacidade funcional na percepção de mulheres da terceira idade frequentadoras de um grupo de dança
}

\author{
Vanessa Pizzol ${ }^{\star}$, Marta Fuentes-Rojas
}

\begin{abstract}
Resumo
É no processo de envelhecimento em que se percebe a redução da capacidade funcional, entendida como: manutenção da flexibilidade, agilidade, equilíbrio dinâmico, resistência de força, coordenação motora e resistência aeróbia para um viver autônomo e independente. Estudos apontam que a dança estimula todos os componentes da capacidade funcional, promovendo a recuperação dela, permitindo ao indivíduo maior independência na vida cotidiana e melhorando sua autoestima. O objetivo foi verificar as contribuições da dança na recuperação da capacidade funcional em mulheres idosas. Estudo qualitativo do tipo descritivo. Participaram 30 mulheres frequentadoras de um grupo de dança. Encontrou-se que, elas percebem que a dança contribui com a recuperação da sua capacidade funcional. Os motivos que levam a prática da dança apontados pelas mulheres foram: melhoras na saúde, na dor, no movimento do corpo, promove a alegria e para muitas o motivo foi a prescrição médica. Conclue-se que a dança não só contribui com a recuperação da capacidade funcional como no social e emocional daquelas que dela participam.
\end{abstract}

\section{Palavras-chave: Capacidade Funcional, Mulheres Idosas, Dança}

\section{Introdução}

A capacidade funcional encontra-se totalmente ligada ao processo de envelhecimento, pois é nesse processo em que começa a ocorrer uma regressão no desempenho das atividades diárias, tendo um impacto negativo na vida das pessoas idosas. É perceptível a perda da capacidade funcional quando ocorre uma regressão no desempenho das atividades diárias como: subir uma escada, lavar louça, e outras. (Alano, 2009). Estudos realizados por Echeverry (2002), afirmam que a dança é bem aceita pelos idosos, principalmente pelas mulheres, pois a dança resgata nas pessoas memórias vividas durante sua trajetória, e consegue unir o bem estar com a qualidade de vida promovendo a recuperação da capacidade funcional, permitindo ao indivíduo independência na vida cotidiana, trazendo de volta a sua autoimagem, sua autoestima e sua autonomia. Se a dança promove a recuperação da capacidade funcional, cabe perguntarmos se as mulheres idosas praticantes da dança conseguem perceber esta recuperação? O objetivo foi verificar na fala das mulheres as contribuições da dança na recuperação da capacidade funcional.

\section{Resultados e Discussão}

O estudo qualitativo do tipo descritivo, com uma amostra de 30 mulheres idosas frequentadoras de um grupo de dança. Foi realizado entrevistas semiestruturadas, no local em que acontece o grupo de dança. E identificadas categorias de análise a partir dos depoimentos. Categorias: Frequência no grupo de dança, tempo que dança, como eram as atividades diárias antes e depois da dança, outras atividades além da dança, e outras. Através da análise das entrevistas, foi possível identificar dois pontos importantes: A identificação da recuperação capacidade funcional na percepção dos sujeitos, e os principais motivos que fazem com que as mulheres busquem a prática da dança como atividade física. Em depoimentos, foi possível identificar em sua maioria a relação da dor com a percepção da capacidade funcional através de falas como: "Antes da dança eu tinha muita dor na articulação, hoje com a dança não sinto mais dor".
Tabela 1. Percepção da recuperação da Capacidade Funcional

\begin{tabular}{|l|r|}
\hline Capacidade funcional & 24 mulheres \\
\hline Saúde & 14 mulheres \\
\hline Socialização & 10 mulheres \\
\hline Bem estar & 17 mulheres \\
\hline
\end{tabular}

Tabela 2. Motivos para a prática da dança como atividade física

\begin{tabular}{|l|r|}
\hline Melhora da saúde & 14 mulheres \\
\hline Melhora da dor & 19 mulheres \\
\hline Melhora dos movimentos do corpo & 11 mulheres \\
\hline Dança por indicação médica & 3 mulheres \\
\hline Dança é alegria/felicidade & 18 mulheres \\
\hline
\end{tabular}

Observou-se também que a dança promove alegria e permite a socialização para quem a prática. Em suas falas, destacaram que essa socialização faz com que as mulheres idosas tenham prazer em realizar a prática da dança com frequência.

\section{Conclusões}

Conclui-se que sim, as mulheres percebem a recuperação da capacidade funcional através da dança. Observou-se um preconceito das mulheres em dizer que a regressão da capacidade funcional provoca a perda de sua independência, e em admitir que necessitavam de ajuda para a realização das atividades diárias antes da dança. Ao falar sobre dores no corpo, em suas falas associaram a melhora da dor com a recuperação da capacidade funcional. Afirmaram, que antes da dança não conseguiam subir uma escada devido a dor, e depois da dança afirmaram que agora conseguem por não sentirem mais dor. Percebeu-se também que a dança é um forte instrumento de motivação para a prática da atividade física, pois além de desenvolver a capacidade funcional proporciona alegria e socialização ao praticante, tornando-se assim um instrumento motivacional para a prática da atividade física.

\section{Agradecimentos}

Ao PIBIC/CNPq pelo fornecimento da bolsa.

${ }^{1}$ Alano, V.R.; Silva, C.J.K.; Vanzuita, A.; Siqueira Filho,V.; Composição e imagem corporal dos frequentadores das academias da terceira idade., 2009.

${ }^{2}$ Echeverry, L.G.J.; Peña, N.M. La danza y el baile, 2002. 